\title{
The 2007-2009 Financial Crisis on Emerging Markets: Quantitative Identification of Crisis in Continent-based Regions
}

\author{
Joanna Olbrys \\ Bialystok University of Technology, Bialystok, Poland \\ Elzbieta Majewska \\ University of Bialystok, Bialystok, Poland
}

\begin{abstract}
This paper focuses on a direct quantitative identification of crisis periods in selected emerging stock markets from four continent-based regions of Europe, Latin America, East Asia, and Middle East and North Africa (MENA), in the context of an influence of the 2007 U.S. subprime financial crisis. The 17 emerging stock markets and, for comparison, the U.S. stock market are investigated. A statistical method of dividing market states into bullish and bearish markets, based on monthly logarithmic returns of major stock market indexes, is employed. The analyzed sample period begins in January 2003 and ends in December 2013. As there is no unanimity in the literature about the crisis periods in the continent-based regions, a formal statistical identification of crises is worthwhile to conduct. Furthermore, the effect of increasing cross-market correlations in the crisis compared to the pre-crisis period in the context of contagion is examining. To address this issue, both standard contemporaneous cross-correlations and volatility-adjusted cross-correlations are applied. The results are consistent with the literature and confirm that tests for contagion based on cross-market correlations are problematic due to the bias introduced by changing volatility in market returns. As contagion can be confused with globalization, the globalization tests in the group of international investigated markets are employed. The results generally do not confirm a global world market integration effect, i.e. there is no reason to reject the research hypothesis of no globalization during the 2007-2009 financial crisis.
\end{abstract}

Keywords: emerging markets, market states, cross-market correlations, contagion, globalization

\section{Introduction}

The main goal of this study is a direct statistical identification of crisis periods on selected emerging stock markets from four continent-based regions of Europe, Latin America, East Asia, and MENA, in the context of the influence of the 2007 U.S. subprime financial crisis. Additionally, the empirical results enable us to observe whether crisis periods were common in different countries of the world. The 17 emerging stock markets and, for comparison, the U.S. stock market are analyzed. Due to free availability of raw data for all the countries

Joanna Olbrys, Ph.D., assistant professor, Faculty of Computer Science, Bialystok University of Technology, Bialystok, Poland.

Elzbieta Majewska, Ph.D., assistant professor, Faculty of Mathematics and Computer Science, University of Bialystok, Bialystok, Poland.

Correspondence concerning this article should be addressed to Joanna Olbrys, Faculty of Computer Science, Bialystok University of Technology, Wiejska 45A, 15-351 Bialystok, Poland. E-mail: j.olbrys@ pb.edu.pl. 
investigated, the sample period begins in January 2003 and ends in December 2013, and it includes the 2007 U.S. subprime crisis period.

Kearney (2012) pointed out that although the term "emerging market" is in common usage, there is no agreement on either the theoretical or operational definition of what it constitutes, and the classification of countries as emerging markets is consequently somewhat arbitrary. Likewise, there are many ways to divide the world's countries into geographic regions, for details see Kearney (2012) and the references therein. In this research, the following countries classified in the literature as emerging markets from four continent-based regions, e.g. Bekaert, Harvey, and Ng (2005); Dooley and Hutchison (2009); Mun and Brooks (2012); Kearney (2012); Calomiris, Love, and Martinez Peria (2012), are selected:

(1) Europe: Russia, Turkey, Poland, the Czech Republic, and Hungary;

(2) Latin America: Brazil, Mexico, Chile, and Argentina;

(3) East Asia: China, India, and Malaysia;

(4) MENA: Israel, Morocco, Tunisia, and Jordan.

To detect for crisis periods in different countries from the continent-based regions, the method of dividing market states into bullish and bearish markets is employed (Pagan \& Sossounov, 2003). As there is no unanimity in research about the crisis periods in the continent-based regions, a formal statistical identification of crises is undoubtedly worthwhile to conduct. As a matter of fact, researchers quite often establish the pre-, post- and crisis periods arbitrarily. A precise identification of crises allows providing sensitivity analysis of relationships and linkages among international stock markets using econometric and statistical tools, with respect to different periods. According to the finance literature, an important problem is verifying to what extent the results obtained during research depend on the choice of the period investigated, especially taking the pre-, post- and crisis periods into consideration.

Furthermore, this paper examines the effect of increasing cross-market correlations in the crisis period compared to the pre-crisis period in the context of contagion, applying both standard contemporaneous cross-market correlations and volatility-adjusted correlation coefficients proposed by Forbes and Rigobon (2002). The research hypothesis of no contagion effect in the continent-based regions during the 2007-2009 financial crisis is tested. The results are in accordance with the results presented in the literature and confirm that tests for contagion based on cross-market correlations are problematic due to the bias introduced by changing volatility in market returns. Bekaert, Ehrmann, Fratzscher, and Mehl (2014) stressed that the 2007-2009 financial crisis has been the first truly major global crisis since the 1929-1932 Great Depression. Because the crisis affected markets worldwide, it revived the debate about presence and sources of contagion in equity markets.

As contagion can be confused with globalization since both have a tendency to increase correlations among markets, especially during periods of high volatility coupled with down markets (Brière, Chapelle, \& Szafarz, 2012, p. 1730), additionally globalization tests in the group of international markets investigated are employed. Jennrich (1970) and Larntz and Perlman (1985) made the procedures, both of which for testing equality of correlation matrices computed over non-overlapping subsamples (the pre-crisis and crisis periods) are used. The results generally do not confirm any global world market integration effect, i.e. there is no reason to reject the null hypothesis of no globalization during the 2007-2009 financial crisis.

To the best of the authors' knowledge, no such research has been undertaken jointly for the group of 17 emerging markets from four continent-based regions and the U.S. stock market. 
The remainder of this study is organized as follows. Section 2 presents a literature review of the influence of the 2007 U.S. subprime financial crisis on emerging markets in the world. Section 3 specifies a methodological background of the statistical method for direct identification of crisis periods. Section 4 proposes a brief analysis of the evidence of increasing cross-market correlations in bear markets, both in the context of contagion and globalization effects. Section 5 presents data description and empirical results on the U.S. and 17 indexes on the emerging stock markets. Section 6 recalls the main findings and presents the conclusions.

\section{The 2007 U.S. Subprime Financial Crisis-Influence on Emerging Markets}

The influence and consequences of the 2007 U.S. subprime crisis for both developed and emerging stock markets in the world have been amply reported in the literature. As interested in the emerging markets from four continent-based regions of Europe, Latin America, East Asia, and MENA, the analysis of previous literature is focused on the broadly-based studies related mostly to emerging economies.

According to the literature, e.g. Brunnermeier (2009) and Claessens, Dell'Ariccia, Igan, and Laeven (2010) among others, the financial crisis timeline, from the U.S. perspective, was marked by the following events: (1) the increase in subprime delinquency rates in the spring of 2007, (2) the ensuing liquidity crunch in late 2007 , (3) the liquidation of Bear Stearns in March 2008, and (4) the failure of Lehman Brothers in September 2008. The U.S. economy officially entered recession following the peak in December 2007, that is in 2008Q1.

In light of the recently growing literature, the crisis began in the U.S., but it did not affect all equity markets to the same extent. The 2007 U.S. subprime financial crisis initially did not fully and strongly affect the emerging markets in the world. Undoubtedly, the Lehman collapse on September 15, 2008 has been a key event, in both the developed economies and the emerging countries. Claessens et al. (2010) recognized five groups of both developed and emerging countries based on the date they were affected by the crisis. They advocated that Turkey and Hungary entered recession in 2008Q2, Chile, Mexico, and Morocco slipped into recession in 2008Q3, while the other emerging countries investigated in our research entered recession in 2008Q4. Recessions are identified by negative real GDP growth rate (Claessens et al., 2010, p. 278). Lane and Milesi-Ferretti (2011) engaged in the geographical impact of the recent global financial crisis. They prepared interesting rankings of region-based groups of countries among the most and least affected by the crisis.

As mentioned in introduction, there is no unanimity in research about the crisis periods in the continent-based regions, as well as the global crisis period in the world. In particular, there is no agreement about the pre-, post-, and crisis periods. Among others, Dooley and Hutchison (2009) investigated the links between the U.S. and a broad range of emerging markets over a subprime crisis period from February 2007 to March 2009. They analyzed three phases of the subprime crisis: (1) from February 27, 2007 to May 18, 2008; (2) from May 19, 2008 to September 14, 2008; and (3) from September 15, 2008 to February 2009. They evaluated the transmission of the U.S. subprime crisis to emerging markets and they found that emerging markets appeared to be somewhat insulated from developments in the U.S. financial market from early 2007 to summer 2008. Mun and Brooks (2012) extended Dooley and Hutchison's analysis to a broader set of developed and emerging markets and also extended the whole sample period to February 2010. They proposed four subsamples/phases of the whole sample period, and the last one from February 20, 2009 to February 26, 2010. Both results of Dooley and Hutchison (2009) and Mun and Brooks (2012) support the decoupling-recoupling hypothesis for emerging markets. Bartram and Bodnar (2009, p. 1273) presented a 
detailed investigation of the global financial crisis 2008/2009, provided a timeline of events and policy actions for the crisis in equity markets, and advocated September 15, 2008 to October 27, 2008 as the common crisis period in the world. Frank and Hesse (2009) found that end of February, 2007 was a period when early signs of stress began to emerge in global markets prior to the time when the subprime crisis was revealed in mid-2007. They stressed that emerging markets were less affected during the initial stages of the subprime crisis than advanced economies. Lagoarde-Segot and Lucey (2009, p. 1486) proposed August 1, 2008 to March 23, 2009 as the common period of the recent global financial crisis in the world. In the research by Calomiris et al. (2012, p. 751), the global crisis period was defined as the period between August 2007 and December 2008. Chudik and Fratzscher (2011) established January 1, 2005 to August 6, 2007 as the pre-crisis period and August 7, 2007 to the end of July, 2009 as a common crisis period for both advanced and emerging economies in the world. They investigated six regional groups: (1) the U.S. market, (2) the advanced European markets, (3) the other advanced economies, (4) the emerging Asian countries, (5) the emerging European countries, and (6) the Latin America region. Didier, Love, and Martinez Peria (2012) engaged in stock market comovements during the 2007-2009 crisis and they investigated 83 stock markets from various regions. Their analysis distinguished between the period before and after the collapse of Lehman Brothers on September 15, 2008.

The causes and consequences of the recent 2007-2009 global financial crisis in different continent-based regions have been amply reported in the literature, especially in the context of various stock markets linkages or contagion effect, such as: Marer (2010) and Olbrys and Majewska (2014b) for Central and Eastern European countries, Ocampo (2009) for Latin American economies, Yilmaz (2010) for East Asian equity markets; and Lagoarde-Segot and Lucey (2009) and Neaime (2012) for the MENA region. Furthermore, the aftermath of financial crises in general was investigated by Reinhart and Rogoff (2009). On the other hand, Rose and Spiegel (2012) focused on national causes and consequences of the recent global financial crisis in the case of 107 countries, ignoring cross-country linkages and contagion effects.

\section{Statistical Procedure for Direct Identification of Crisis Periods}

According to the literature, a direct identification of crisis periods is possible based on statistical procedures for dividing market states into up and down markets, for example, in the study of Cooper, Gutierrez, and Hameed (2004), a bull market - a up market (a bear market - a down market) was identified when the past 12-, 24-, or 36-month market return was non-negative (negative), respectively. The identification of market states is a problem of considerable importance, as Cooper et al. (2004) among others obtained that profits to investment strategies depend critically on the state of the market. Lunde and Timmermann (2000) proposed an algorithm for detecting bull and bear states, however, they stressed that there is no generally accepted formal definition of up and down markets in finance literature. The authors investigated a new type of long-run dependence in stock prices based on the distribution of time spent in markets where cumulated returns exceed some positive threshold value (bull states) or fall below some negative threshold value (bear states).

Pagan and Sossounov (2003) developed an algorithm that seemed to be successful in locating periods in time that were considered bull and bear markets in the U.S. equity prices. They tested monthly data of the S\&P500 index, in the period from January 1835 to May 1997. Lee, Kuo, and Yen (2011) proposed a modified version of the Pagan and Sossounov's method of dividing market states into bullish, bearish, and range-bound 
markets. Authors employ a three-stage procedure of dividing market states into up and down markets (Olbrys \& Majewska, 2014a). Our methodology builds on Pagan and Sossounov's method. In the first step, a preliminary identification of turning points was conducted, i.e., peaks and troughs, based on the conditions (1) and (2), respectively:

$$
\begin{aligned}
& \ln P_{t-8}, \ldots, \ln P_{t-1}<\ln P_{t}>\ln P_{t+1}, \ldots, \ln P_{t+8} \\
& \ln P_{t-8}, \ldots, \ln P_{t-1}>\ln P_{t}<\ln P_{t+1}, \ldots, \ln P_{t+8}
\end{aligned}
$$

where $P_{t}$ represents the market index of month $t$, and from successive peaks/troughs, the highest/deepest one is choosed, respectively. Pagan and Sossounov (2003) stressed that in the cycle literature, an algorithm for describing turning points in time series was developed by Bry and Boschan (1971), but they modified this algorithm by taking the eight months window (instead of six) in marking the initial location of turning points. In the second step, the phases (peak-trough or trough-peak) that last for less than four months and cycles (peak-trough-peak or trough-peak-trough) that last for less than 16 months are ruled out. Pagan and Sossounov (2003) pointed out that in cycle dating, the minimal cycle length is 15 months, hence 16 months was chosen to create a symmetric window of eight periods. Moreover, they advocated four months as the minimal length of a phase. In the last step, authors calculate the amplitudes $A$ for each phase (amplitude is the difference in the natural $\operatorname{logs}$ of the index value in subsequent turning points). During the bull/bear market period, there must be a large enough (of at least 20\%) rise/fall in the index value. This means that the amplitude of a given phase must fulfill the condition $A \geq 0.18$ or $A \leq-0.22$ for the bull or bear market period, respectively (Olbrys \& Majewska, 2014a, p. 255).

\section{Evidence of Increasing Cross-market Correlations in Crisis Periods}

The literature has shown that international stock market correlation is an undoubtedly crucial topic because of many practical implications, especially in the context of market globalization as well as an international portfolio choice and diversification. According to the portfolio theory, motivations and gains of international diversification rely on low correlations across stock markets in the world. In their broadly cited paper, Longin and Solnik (2001) studied the conditional correlation structure of international equity returns and derived a formal statistical method, based on the extreme value theory. They found that conditional correlation increases in bear markets, but not in bull markets. Goetzmann, Li, and Rouwenhorst (2005) examined the correlation structure of the major world markets over 150 years. They found that international equity correlations change dramatically through time, thus the diversification benefits to global investing are not constant. Hong, Tu, and Zhou (2007) provided a model-free test for asymmetric correlations in bear markets versus bull markets. They evaluated the economic significance of incorporating asymmetries into investment decisions.

\section{Contagion Tests}

Although there is no unanimity in research regarding the reasons of increasing cross-market correlations in crisis periods, the majority of researchers agree that during critical market events, correlations change substantially. This effect is often justified by the authors as the consequence of contagion, but undoubtedly contagion is not simply revealed by increased correlation of market returns during a crisis period. Edwards (2000) stressed that contagion has been defined in the economic literature in many different ways, including as 
any transmission of shocks across countries. He distinguished among three mechanisms through which economic shocks are propagated across countries: (1) global disturbances that affect all (or most) countries in the world, (2) shocks coming from a related country, and (3) all instances not covered by the two previous cases, in which contagion is defined as a residual, and thus as a situation where the extent and magnitude of the international transmission of shocks exceeds what was expected by market participants, for more details see Edwards (2000) and the references therein. Pericoli and Sbracia (2003) presented five definitions of contagion adopted by the literature and the corresponding measures used in empirical work. However, they found that early studies did not always distinguish between contagion and interdependence. The authors stressed that definitions and measures of contagion work well in the presence of an unambiguous identification of financial crisis. Bekaert et al. (2005) defined contagion as excess correlation, that is, correlation over and above what one would expect from economic fundamentals. They engaged contagion from an asset pricing perspective and they expressed it by correlation of the factor model residuals.

As argued by Rigobon (2002, p. 4), there is no accordance on what contagion means. In this vein, Forbes and Rigobon (2002) defined contagion as a significant increase in cross-market linkages after a shock to one country (or group of countries), but they stated that this definition is not universally accepted. They stressed that heteroskedasticity in market returns biases tests for contagion based on correlation and correlation coefficients are conditional on market volatility, and therefore they proposed the following correction for the volatility bias:

$$
\hat{\rho}_{V A}=\frac{\hat{\rho}_{C}}{\sqrt{1+\delta\left[1-\left(\hat{\rho}_{C}\right)^{2}\right]}}
$$

where $\hat{\rho}_{V A}$ is the volatility-adjusted cross-correlation coefficient between markets, $\hat{\rho}_{C}$ is the estimated conditional cross-correlation coefficient in the crisis period, and $\delta$ is the relative increase in the variance of market returns in the crisis period compared to the pre-crisis period:

$$
\delta=\frac{\hat{\sigma}_{C}^{2}}{\hat{\sigma}_{P C}^{2}}-1
$$

where $\hat{\sigma}_{C}^{2}$ and $\hat{\sigma}_{P C}^{2}$ are the variances in the high-volatility (crisis) and low-volatility (pre-crisis) periods, respectively. By construction, it is obvious that $\hat{\rho}_{V A} \leq \hat{\rho}_{C}$, i.e. during the periods of high volatility, the unconditional volatility-adjusted cross-correlation $\hat{\rho}_{V A}$ will be smaller than the estimated conditional cross-correlation $\hat{\rho}_{C}$ between markets. The evaluation of contagion is carried out by testing the hypotheses:

$$
\begin{aligned}
& \mathrm{H}_{0}: \rho_{V A}=\rho_{P C} \\
& \mathrm{H}_{1}: \rho_{V A} \neq \rho_{P C}
\end{aligned}
$$

where $\rho_{P C}$ is the cross-correlation coefficient in the pre-crisis period and the null hypothesis states that there is no contagion. The $Z$-statistic, which is asymptotically a standard normal random variable, tests null of no contagion, that is, the equality of the crisis with pre-crisis cross-market correlation coefficients. The test is performed with the Fisher's $z$-transformation (1921) of sample correlation coefficients. If the absolute value of the $Z$-statistic is greater than the critical value, the null hypothesis of identical correlation coefficients can be rejected (Olbrys \& Majewska, 2014b).

\section{Globalization Tests}

According to the literature, the evidence is that contagion can be confused with market integration since both have tendency to increase correlations among markets, especially during down market periods. Growing 
international integration could lead to a progressive increase in market correlations, and markets could be more correlated in periods of high volatility (Longin \& Solnik, 1995, p. 6). Bekaert et al. (2005) pointed out that integration can be regional or global. Global world market integration can be named as globalization. Therefore, authors employ tests interpreted as globalization tests in the broad-based group of international markets investigated using formal procedures for testing equality of correlation matrices computed over non-overlapping subsamples, e.g., Jennrich (1970), Larntz and Perlman (1985), Longin and Solnik (1995), Chesnay and Jondeau (2001), Goetzmann et al. (2005), and Brière et al. (2012). The evaluation of globalization is carried out by testing the hypotheses:

$$
\begin{aligned}
& \mathrm{H}_{0}: P_{C}=P_{P C} \\
& \mathrm{H}_{1}: P_{C} \neq P_{P C}
\end{aligned}
$$

where $P_{C}$ and $P_{P C}$ are true (population) correlation matrices in the crisis and pre-crisis periods, respectively, and the null hypothesis states that there is no integration effect during crises.

Different test statistics have been proposed in the literature to test the problem (6). One of the most popular is the test introduced by Jennrich (1970). Let $\hat{P}_{C}=\left(\hat{\rho}_{i j}^{C}\right)$ and $\hat{P}_{P C}=\left(\hat{\rho}_{i j}^{P C}\right)$ be sample correlation matrices in the crisis and pre-crisis periods of sample size $n_{C}$ and $n_{P C}$, respectively. The average correlation matrix is equal to $\hat{P}=\frac{1}{n_{C}+n_{P C}}\left(n_{C} \hat{P}_{C}+n_{P C} \hat{P}_{P C}\right), \hat{P}=\left(\hat{\rho}_{i j}\right)$ and $\hat{P}^{-1}=\left(\hat{\rho}^{i j}\right)$. As authors investigate dependencies in two subsamples of equal size $n_{C}=n_{P C}=n$, the following version of the Jennrich (1970) test statistic $T_{J}$ is employed:

$$
T_{J}=\frac{1}{2} \operatorname{tr}\left(Z^{2}\right)-\operatorname{diag}(Z)^{\prime} \times S^{-1} \times \operatorname{diag}(Z)
$$

where $Z$ is a square matrix given by the following equation:

$$
Z=\sqrt{\frac{n}{2}} \times \hat{P}^{-1} \times\left(\hat{P}_{C}-\hat{P}_{P C}\right)
$$

and matrix $S=\left(\delta_{i j}+\hat{\rho}_{i j} \cdot \hat{\rho}^{i j}\right)$, where $\delta_{i j}$ is the Kronecker's delta. In equation (7), $\operatorname{diag}(Z)$ denotes the diagonal of the matrix $Z$ (8) in a column form. The Jennrich's test statistic $T_{J}$ has an asymptotic $\chi^{2}(p(p-1) / 2)$ distribution, if the correlation matrix is computed for $p$ variables. If the value of the $T_{J}$ statistic (7) is greater than the critical value, the null hypothesis of identical correlation matrices can be rejected.

Although the Jennrich's test statistic (7) is quite popular in the literature, Larntz and Perlman (1985) pointed out that this test is basically a large sample test and can perform poorly for small samples. They proposed a test statistic $T_{L P}$ which determined a test with reasonable small sample properties and with power comparable to that of Jennrich's test (7) for large samples (Larntz \& Perlman, 1985, p. 3). The basic idea is to apply the Fisher's $z$-transformation to each sample correlation coefficient in the correlation matrices $\hat{P}_{C}=\left(\hat{\rho}_{i j}^{C}\right)$ and $\hat{P}_{P C}=\left(\hat{\rho}_{i j}^{P C}\right)$, and to consider the $(p(p-1) / 2)$ dimensional random column vectors consisting of the off-diagonal $z$-transformations $(1 \leq i<j \leq p)$ arranged in lexicographic order. In the case of two subsamples of equal size $n_{C}=n_{P C}=n$, authors use the following version of the Larntz and Perlman's test statistic $T_{L P}$ :

$$
T_{L P}=\sqrt{\frac{(n-3)^{2}}{2 n-6}} \max _{1 \leq i<j \leq p}\left|z_{i j}^{C}-z_{i j}^{P C}\right|
$$


where $z_{i j}^{C}$ and $z_{i j}^{P C}$ are the Fisher's $z$-transformations of sample correlation coefficients $\hat{\rho}_{i j}^{C}$ and $\hat{\rho}_{i j}^{P C}$, respectively. Larntz and Perlman proposed the significance level $\alpha$ test under which the null (6) is rejected if $T_{L P}>b_{\alpha}$, where $b_{\alpha}>0$ is chosen such that $\left(\Phi\left(b_{\alpha}\right)-\Phi\left(-b_{\alpha}\right)\right)^{p(p-1) / 2}=1-\alpha$, and $\Phi$ is the cumulative distribution function of the standard normal distribution.

Based on the cases studied, Larntz and Perlman proposed the following rule-of-thumb: When the ratio of sample size to dimension does not exceed 4, i.e. when $(n / p) \leq 4$, then the $T_{L P}$ test statistic (9) is recommended (Larntz \& Perlman, 1985, p. 9). As the sample size $n \rightarrow \infty$, both the tests of Jennrich and Larntz and Perlman are asymptotically consistent.

\section{Data Description and Empirical Results in the U.S. and Emerging Stock Markets}

The data consists of monthly logarithmic returns of selected emerging stock market indexes and the New York market index-S\&P500. There are 132 monthly observations in each series for the period beginning in January 2003 and ending in December 2013. The period contains all data necessary to employ the procedure described in Section 3. In this research, our own database is used, not a commercial one.

\section{Preliminary Statistics}

Table 1 contains brief information about the major emerging stock market indexes analyzed in the study, in order to decrease value of market capitalization at the end of 2012.

Table 1

Major Emerging Stock Market Indexes Used in the Study

\begin{tabular}{|c|c|c|c|c|}
\hline & & Market & $\begin{array}{l}\text { Market Cap., USD billion, } \\
\text { December } 2012\end{array}$ & Index \\
\hline \multirow{5}{*}{ Europe } & 1 & Moscow Exchange (Russia) & 825.3 & RTSI \\
\hline & 2 & Istanbul Stock Exchange (Turkey) & 315.2 & BIST100 \\
\hline & 3 & Warsaw Stock Exchange (Poland) & 177.4 & WIG \\
\hline & 4 & Prague Stock Exchange (the Czech Republic) & 37.1 & PX \\
\hline & 5 & Budapest Stock Exchange (Hungary) & 20.8 & BUX \\
\hline \multirow{4}{*}{\multicolumn{2}{|c|}{ Latin America }} & Sao Paulo Stock Exchange (Brazil) & $1,227.4$ & BOVESPA \\
\hline & & Mexican Stock Exchange (Mexico) & 525.1 & IPC \\
\hline & & Santiago Stock Exchange (Chile) & 313.3 & IPSA \\
\hline & 4 & Buenos Aires Stock Exchange (Argentina) & 34.3 & MERVAL \\
\hline \multirow{4}{*}{\multicolumn{2}{|c|}{ East Asia }} & Shanghai Stock Exchange (China) & $2,547.2$ & SSE Composite \\
\hline & & Bombay Stock Exchange (India) & $1,263.3$ & S\&P BSE SENSEX \\
\hline & & Taiwan Stock Exchange (Taiwan) & 735.3 & TAIEX \\
\hline & & Bursa Malaysia (Malaysia) & 466.6 & FTSE Bursa Malaysia KLCI \\
\hline \multirow{4}{*}{$\begin{array}{l}\text { Middle East and } \\
\text { North Africa }\end{array}$} & 1 & Tel Aviv Stock Exchange (Israel) & 161.9 & TA100 \\
\hline & & Casablanca Stock Exchange (Morocco) & 52.5 & MASI \\
\hline & 3 & Tunis Stock Exchange (Tunisia) & 28.2 & TUNINDEX \\
\hline & 4 & Amman Stock Exchange (Jordan) & 27.0 & Amman SE All Share \\
\hline
\end{tabular}

Source: http://fese.eu/en/; http://www.world-exchanges.org; national stock exchange websites.

Table 2 reports summarized statistics for the monthly logarithmic returns for the S\&P500 and 17 stock indexes of emerging markets, as well as statistics testing for normality. 
Table 2

Summarized Statistics for the Monthly Logarithmic Returns for Stock Market Indexes Used in the Study

\begin{tabular}{|c|c|c|c|c|c|c|}
\hline & Index & Mean & $\begin{array}{l}\text { Standard } \\
\text { deviation }\end{array}$ & Skewness & Excess kurtosis & $\begin{array}{l}\text { Doornik and } \\
\text { Hansen's test }\end{array}$ \\
\hline \multirow[t]{3}{*}{ U.S. } & S\&P500 & 0.006 & 0.042 & $-1.090[0.000]$ & $2.951[0.000]$ & $20.368[0.000]$ \\
\hline & RTSI & 0.011 & 0.104 & $-1.005[0.000]$ & $2.635[0.000]$ & $18.251[0.000]$ \\
\hline & BIST100 & 0.014 & 0.088 & $-0.459[0.033]$ & $0.537[0.210]$ & $4.903[0.086]$ \\
\hline \multirow[t]{4}{*}{ Europe } & WIG & 0.010 & 0.065 & $-0.646[0.003]$ & $2.229[0.000]$ & $16.477[0.000]$ \\
\hline & PX & 0.006 & 0.067 & $-1.283[0.000]$ & $4.406[0.000]$ & $26.384[0.000]$ \\
\hline & BUX & 0.007 & 0.071 & $-0.985[0.000]$ & $3.252[0.000]$ & $20.978[0.000]$ \\
\hline & BOVESPA & 0.012 & 0.066 & $-0.632[0.004]$ & $1.893[0.000]$ & $13.509[0.001]$ \\
\hline \multirow{3}{*}{ Latin America } & IPC & 0.015 & 0.050 & $-0.818[0.000]$ & $1.793[0.000]$ & $13.325[0.001]$ \\
\hline & IPSA & 0.010 & 0.046 & $0.129[0.545]$ & $0.074[0.863]$ & $0.713[0.670]$ \\
\hline & MERVAL & 0.017 & 0.094 & $-0.941[0.000]$ & $3.833[0.000]$ & $26.655[0.000]$ \\
\hline \multirow{4}{*}{ East Asia } & SSE Composite & 0.003 & 0.085 & $-0.571[0.008]$ & $1.393[0.001]$ & $9.824[0.007]$ \\
\hline & S\&P BSE SENSEX & 0.014 & 0.073 & $-0.577[0.008]$ & $1.897[0.000]$ & $14.019[0.001]$ \\
\hline & TAIEX & 0.004 & 0.061 & $-0.502[0.020]$ & $0.739[0.086]$ & $5.999[0.050]$ \\
\hline & FTSE Bursa Malaysia KLCI & 0.008 & 0.039 & $-0.552[0.011]$ & $2.898[0.000]$ & $26.491[0.000]$ \\
\hline \multirow{4}{*}{$\begin{array}{l}\text { Middle East and } \\
\text { North Africa }\end{array}$} & TA100 & 0.010 & 0.053 & $-0.918[0.000]$ & $2.208[0.000]$ & $15.898[0.000]$ \\
\hline & MASI & 0.008 & 0.048 & $-0.002[0.993]$ & $2.066[0.000]$ & $21.652[0.000]$ \\
\hline & TUNINDEX & 0.011 & 0.038 & $-0.308[0.151]$ & $2.430[0.000]$ & $24.817[0.000]$ \\
\hline & Amman SE All Share & 0.025 & 0.217 & $9.909[0.000]$ & $105.430[0.000]$ & $7,011.530[0.000]$ \\
\hline
\end{tabular}

Notes. The table is based on all sample observations during the period from January 2003 to December 2013; the test statistic for skewness and excess kurtosis is the conventional $t$-statistic; the Doornik and Hansen's test (2008) has an $\chi^{2}$ distribution if the null hypothesis of normality is true; the numbers in brackets are $p$-values.

The empirical results presented in Table 2 are worth a comment. The measure for skewness shows that the return series are skewed, except for the IPSA (Chile), MASI (Morocco), and TUNINDEX (Tunisia) series. The measure for excess kurtosis shows that almost all series are highly leptokurtic with respect to the normal distribution, except for the BIST100 (Turkey), IPSA (Chile), and TAIEX (Taiwan) series. The Doornik and Hansen's test (2008) rejected normality for almost all return series at the five percent level of significance, except for the BIST100 (Turkey), IPSA (Chile), and TAIEX (Taiwan) series.

\section{Direct Identification of Crisis Periods for the U.S. and Emerging Stock Markets}

As stated in Section 3, the three-stage procedure of dividing market states into bullish and bearish markets to identify crisis periods is employed. Figures 1 and 2 present the crisis periods for the S\&P500 and 17 indexes on the emerging stock markets obtained from the procedure. The empirical results are generated in the whole sample period from January 2003 to December 2013. The horizontal axis stands for time (months), and the vertical axis stands for the market index. The vertical lines and light grey areas stand for the crisis periods.

The following crisis periods for the emerging markets from four continent-based regions are obtained:

(1) Europe: from May 2008 to January 2009 (Russia), from October 2007 to February 2009 (Turkey), from June 2007 to February 2009 (Poland), from October 2007 to February 2009 (the Czech Republic), and from July 2007 to February 2009 (Hungary);

(2) Latin America: from May 2008 to November 2008 (Brazil), from May 2008 to February 2009 (Mexico), from June 2007 to December 2008 (Chile), and from October 2007 to November 2008 (Argentina); 
(3) East Asia: from October 2007 to October 2008 (China), from December 2007 to February 2009 (India), from October 2007 to January 2009 (Taiwan), and from December 2007 to October 2008 (Malaysia);

(4) MENA: from October 2007 to December 2008 (Israel), from March 2008 to January 2009 (Morocco), from September 2010 to February 2011 (Tunisia), and from June 2008 to July 2012 (Jordan).

Our results confirm January to February 2009 as the end of the crisis period for nine out of 17 emerging countries investigated, as well as for the U.S. stock market.

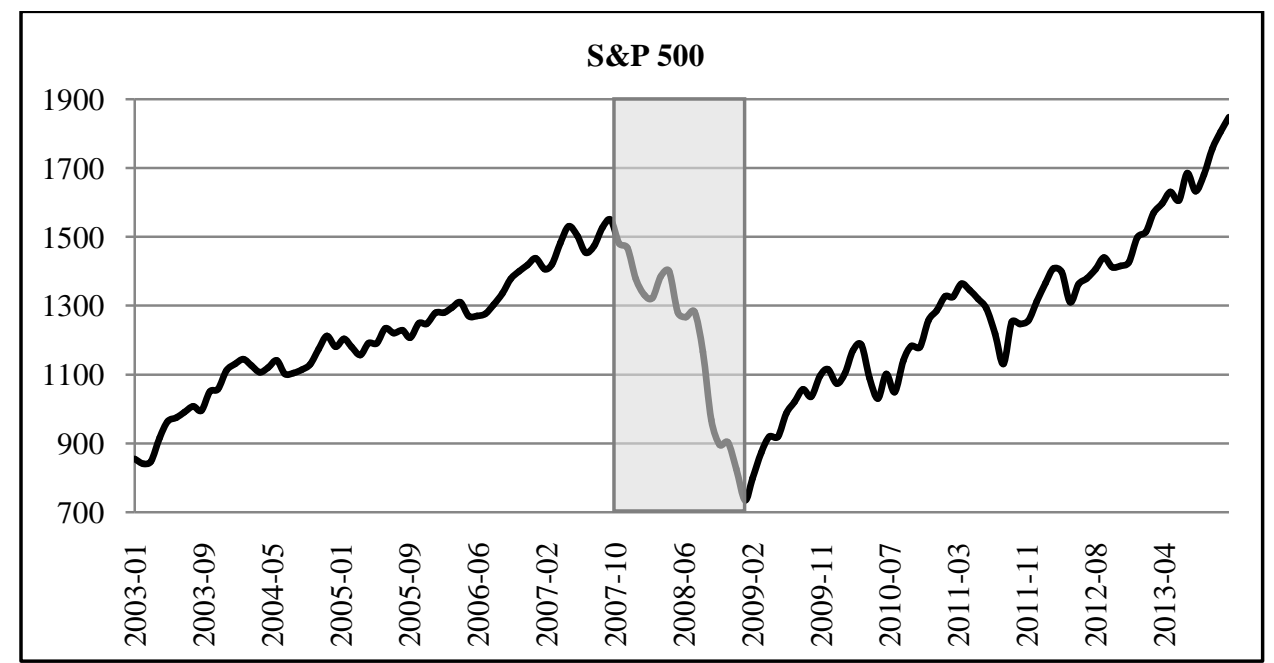

Figure 1. The period from October 2007 to February 2009 as crisis period for the S\&P500 (New York).

\section{Correctness Analysis}

This subsection briefly discusses the correctness of quantitative identification of bear market periods, based on the Pagan and Sossounov's procedure (2003). Two methods for checking the bear market conditions are employed, proposed by Fabozzi and Francis (1977): (1) the up and down market procedure, and (2) the substantial moves procedure. According to the first procedure, the expected index returns were negative during the crisis periods for all stock markets investigated. Therefore, the determined periods were placed in the down category. The second procedure partitioned the sample into three subsets: (1) months when the market moved up substantially, (2) months when the market moved down substantially, and (3) months when the market moved neither up nor down substantially. Substantial moves were arbitrarily defined as months when the absolute value of market return was larger than half of one standard deviation of the market returns measured over the total sampled period (Fabozzi \& Francis, 1977, pp. 1094-1095). Using the second procedure, it can be obtained that during the down market months, the absolute value of the expected market return was larger than half of one standard deviation of the stock market returns measured over the total period for almost all of the markets investigated, except for the Santiago Stock Exchange and the Amman Stock Exchange. In the case of the S\&P500 index, the absolute value of the expected return 0.043 was even almost equal to the standard deviation 0.042. Finally, the empirical results of the first procedure confirmed the bear market periods presented in Figure 1 and 2. The results of the second Fabozzi and Francis procedure were questionable only for two markets mentioned above, but the Jordanian market is especially problematic and different in many respects. 

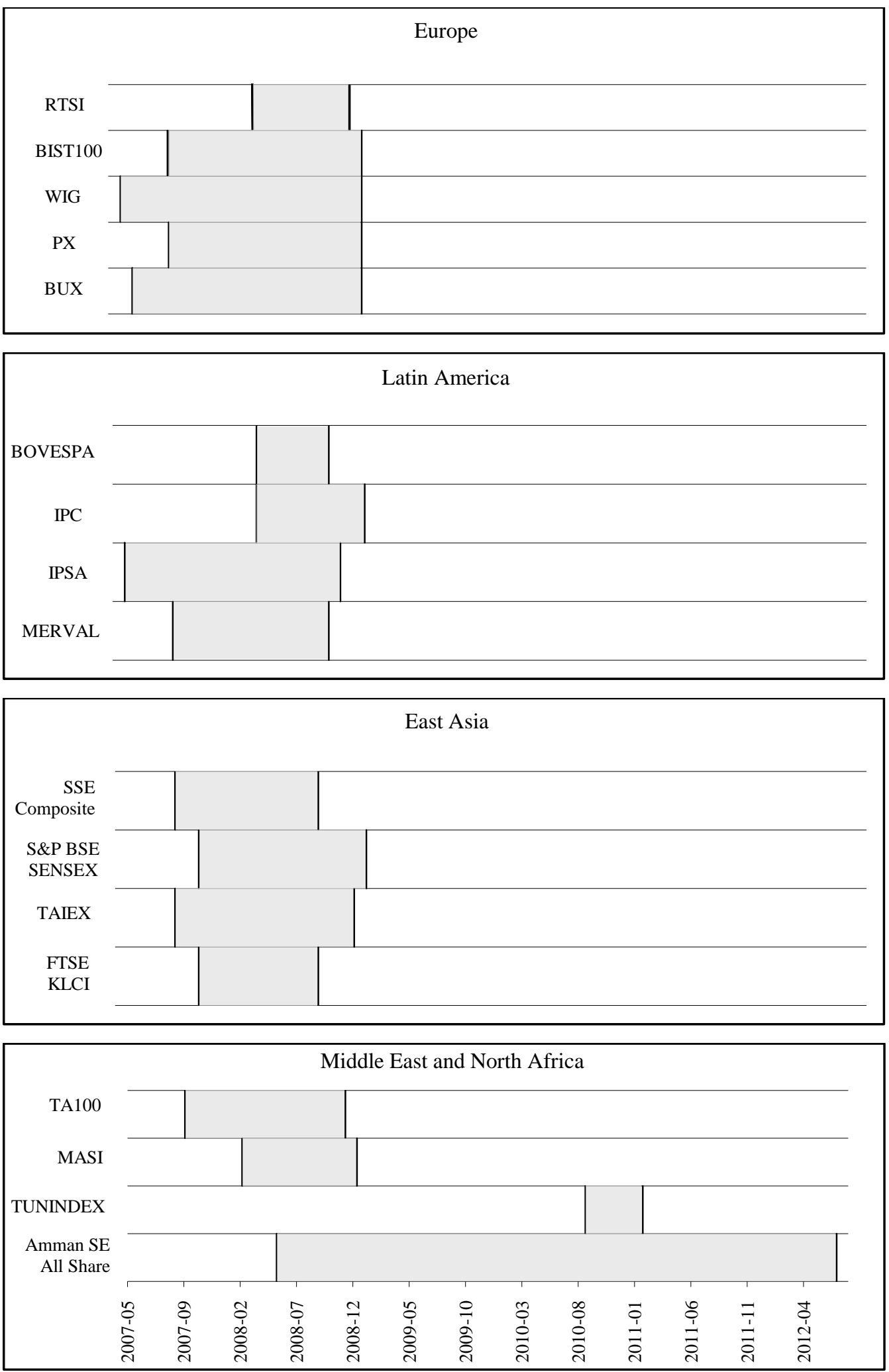

Figure 2. Overall information about the crisis periods on selected emerging stock markets from four continent-based regions of Europe, Latin America, East Asia, and MENA, in the context of the influence of the 2007 U.S. subprime financial crisis. 


\section{Cross-market Correlations in the Context of Contagion}

As mentioned in Section 4, the evidence of significant increased correlation in international equity markets in down market periods has been amply reported in the literature. Our goal is to examine this observation during the recent 2007 U.S. subprime crisis. It was necessary to appoint one date as the beginning (and as the ending) of the crisis period for all countries, therefore June 2007 to February 2009 is suggested as the crisis period. This period covers most of the individual periods established for stock markets investigated in the research (see Figure 2). One can observe in Figure 2 that the results obtained are quite different only in the case of the MENA markets. However, it is not surprising if a lower level of financial and economic world integration of the MENA region is taken into account.

Table 3 contains standard contemporaneous cross-correlations and volatility-adjusted cross-correlation coefficients, given by equation (3), of monthly logarithmic returns on pairs of the indexes S\&P500/stock market index. For comparison, dependencies are calculated both in the whole sample (from January 2003 to December 2013) and in two subsamples of equal size: (1) the pre-crisis period from September 2005 to May 2007 (21 months), and (2) the crisis period from June 2007 to February 2009 (21 months). The cross-market linkages after a shock to the U.S. financial market are investigated. The supporting values are equal to

$\hat{\sigma}_{C}^{2}=0.00333$ (the variance in the high-volatility period in the U.S. stock market), and $\hat{\sigma}_{P C}^{2}=0.00035$ (the variance in the low-volatility period in the U.S. stock market), while the relative increase in the variance of the S\&P500 returns, given by equation (4), is equal to $\delta=8.4347$.

The results confirm that, during the crisis period, the estimated contemporaneous cross-correlations between the U.S. and other markets were greater than the corresponding cross-correlations in the pre-crisis period, except for two cases: the IPSA (Chile) $(\downarrow 31.2 \%)$ and MASI (Morocco) ( $\downarrow 53.4 \%)$ indexes. Based on the contemporaneous cross-market correlations, no reason to reject the null hypothesis of no contagion has been found, except for two indexes, i.e. PX (the Czech Republic) and Amman SE All Share (Jordan). As a matter of fact, the results obtained seem to be rather incidental.

As for the volatility-adjusted cross-correlations, one can observe that the Forbes and Rigobon's correction seems to be a rather strong tool for adjusting cross-market correlation coefficients in the whole sample of countries. Assuming the U.S. financial market as a source of risk and using the coefficient $\delta$ of the relative increase in the variance of the S\&P500 returns in the crisis period compared to the pre-crisis period, a substantial reduction of the value of correlations can be got. Eventually, the volatility-adjusted cross-correlations in the crisis period are lower comparing with the pre-crisis period in the case of all countries investigated, except for two MENA markets in Tunis (Tunisia) and Amman (Jordan). However, one can observe in Table 3 that for the above-mentioned MENA markets the cross-correlation coefficients with the U.S. stock market are not statistically significant at the five percent level in the pre-crisis period. The results are quite different for two of the MENA indexes, i.e. TUNINDEX (Tunisia) and Amman SE All Share (Jordan), but it is not surprising primarily because of the lower level of financial and economic world integration of the MENA region (Neaime, 2012), as well as lack of political and social stability. After employing the Forbes and Rigobon's correction of cross-correlations, the null of no contagion can be rejected only for two out of 17 indexes, i.e. IPSA (Chile) and S\&P BSE SENSEX (India). 
Table 3

Contemporaneous Cross-correlations and Volatility-adjusted Cross-correlations of Monthly Logarithmic Returns on Pairs S\&P500/Stock Market Index

\begin{tabular}{|c|c|c|c|c|c|c|c|c|c|c|c|c|}
\hline & & \multirow{3}{*}{ Index } & \multicolumn{6}{|c|}{ Contemporaneous cross-correlations } & \multicolumn{4}{|c|}{$\begin{array}{l}\text { Volatility-adjusted } \\
\text { cross-correlations }\end{array}$} \\
\hline & & & \multirow{2}{*}{$\begin{array}{l}\text { Whole } \\
\text { sample } \\
(1) \\
\hat{\rho}\end{array}$} & \multicolumn{2}{|l|}{$\begin{array}{l}\text { Pre-crisis } \\
\text { (2) }\end{array}$} & \multicolumn{3}{|c|}{ Crisis (3) } & \multicolumn{4}{|c|}{ Crisis (3) } \\
\hline & & & & $\hat{\rho}_{P C}$ & $\hat{\rho}_{C}$ & $\begin{array}{l}\text { Change } \\
\text { compared } \\
\text { to the } \\
\text { period (2) }\end{array}$ & $Z$-statistic & Contagion & $\hat{\rho}_{V A}$ & $\begin{array}{l}\text { Change } \\
\text { compared } \\
\text { to the } \\
\text { period (2) }\end{array}$ & $Z$-statistic & Contagion \\
\hline \multirow{5}{*}{ Europe } & 1 & RTSI & $\begin{array}{l}0.635 \\
{[0.000]}\end{array}$ & $\begin{array}{l}0.290 \\
{[0.203]}\end{array}$ & $\begin{array}{l}0.674 \\
{[0.001]}\end{array}$ & $\uparrow 132.4 \%$ & 1.558 & $\mathrm{H}_{0}$ & 0.285 & $\downarrow 1.8 \%$ & -0.017 & $\mathrm{H}_{0}$ \\
\hline & 2 & BIST100 & $\begin{array}{l}0.518 \\
{[0.000]}\end{array}$ & $\begin{array}{l}0.587 \\
{[0.005]}\end{array}$ & $\begin{array}{l}0.633 \\
{[0.002]}\end{array}$ & $\uparrow 7.8 \%$ & 0.220 & $\mathrm{H}_{0}$ & 0.257 & $\downarrow 56.2 \%$ & -1.230 & $\mathrm{H}_{0}$ \\
\hline & 3 & WIG & $\begin{array}{l}0.723 \\
{[0.000]}\end{array}$ & $\begin{array}{l}0.551 \\
{[0.010]}\end{array}$ & $\begin{array}{l}0.822 \\
{[0.000]}\end{array}$ & $\uparrow 49.2 \%$ & 1.629 & $\mathrm{H}_{0}$ & 0.425 & $\downarrow 22.8 \%$ & -0.497 & $\mathrm{H}_{0}$ \\
\hline & 4 & PX & $\begin{array}{l}0.726 \\
{[0.000]}\end{array}$ & $\begin{array}{l}0.601 \\
{[0.000]}\end{array}$ & $\begin{array}{l}0.889 \\
{[0.000]}\end{array}$ & $\uparrow 47.9 \%$ & 2.167 & $\mathrm{H}_{1}$ & 0.534 & $\downarrow 11.1 \%$ & -0.296 & $\mathrm{H}_{0}$ \\
\hline & 5 & BUX & $\begin{array}{l}0.720 \\
{[0.000]}\end{array}$ & $\begin{array}{l}0.682 \\
{[0.001]}\end{array}$ & $\begin{array}{l}0.776 \\
{[0.000]}\end{array}$ & $\uparrow 13.8 \%$ & 0.607 & $\mathrm{H}_{0}$ & 0.372 & $\downarrow 45.5 \%$ & -1.327 & $\mathrm{H}_{0}$ \\
\hline \multirow{4}{*}{$\begin{array}{l}\text { Latin } \\
\text { America }\end{array}$} & 1 & BOVESPA & $\begin{array}{l}0.669 \\
{[0.000]}\end{array}$ & $\begin{array}{l}0.654 \\
{[0.001]}\end{array}$ & $\begin{array}{l}0.742 \\
{[0.000]}\end{array}$ & $\uparrow 13.5 \%$ & 0.518 & $\mathrm{H}_{0}$ & 0.339 & $\downarrow 48.2 \%$ & -1.288 & $\mathrm{H}_{0}$ \\
\hline & 2 & IPC & $\begin{array}{l}0.722 \\
{[0.000]}\end{array}$ & $\begin{array}{l}0.635 \\
{[0.002]}\end{array}$ & $\begin{array}{l}0.750 \\
{[0.000]}\end{array}$ & $\uparrow 18.1 \%$ & 0.670 & $\mathrm{H}_{0}$ & 0.346 & $\downarrow 45.5 \%$ & -1.166 & $\mathrm{H}_{0}$ \\
\hline & 3 & IPSA & $\begin{array}{l}0.461 \\
{[0.000]}\end{array}$ & $\begin{array}{l}0.654 \\
{[0.001]}\end{array}$ & $\begin{array}{l}0.450 \\
{[0.041]}\end{array}$ & $\downarrow 31.2 \%$ & -0.893 & $\mathrm{H}_{0}$ & 0.162 & $\downarrow 75.2 \%$ & -1.857 & $\mathrm{H}_{1}$ \\
\hline & 4 & MERVAL & $\begin{array}{l}0.604 \\
{[0.000]}\end{array}$ & $\begin{array}{l}0.528 \\
{[0.014]}\end{array}$ & $\begin{array}{l}0.688 \\
{[0.001]}\end{array}$ & $\uparrow 30.3 \%$ & 0.770 & $\mathrm{H}_{0}$ & 0.295 & $\downarrow 44.1 \%$ & -0.850 & $\mathrm{H}_{0}$ \\
\hline \multirow{4}{*}{$\begin{array}{l}\text { East } \\
\text { Asia }\end{array}$} & 1 & $\begin{array}{l}\text { SSE } \\
\text { Composite }\end{array}$ & $\begin{array}{l}0.372 \\
{[0.000]}\end{array}$ & $\begin{array}{l}0.225 \\
{[0.328]}\end{array}$ & $\begin{array}{l}0.371 \\
{[0.098]}\end{array}$ & $\uparrow 64.9 \%$ & 0.482 & $\mathrm{H}_{0}$ & 0.129 & $\downarrow 42.7 \%$ & -0.298 & $\mathrm{H}_{0}$ \\
\hline & 2 & $\begin{array}{l}\text { S\&P BSE } \\
\text { SENSEX }\end{array}$ & $\begin{array}{l}0.631 \\
{[0.000]}\end{array}$ & $\begin{array}{l}0.778 \\
{[0.000]}\end{array}$ & $\begin{array}{l}0.793 \\
{[0.000]}\end{array}$ & $\uparrow 1.9 \%$ & 0.118 & $\mathrm{H}_{0}$ & 0.390 & $\downarrow 49.8 \%$ & -1.885 & $\mathrm{H}_{1}$ \\
\hline & 3 & TAIEX & $\begin{array}{l}0.642 \\
{[0.000]}\end{array}$ & $\begin{array}{l}0.457 \\
{[0.037]}\end{array}$ & $\begin{array}{l}0.566 \\
0.007]\end{array}$ & $\uparrow 23.8 \%$ & 0.444 & $\mathrm{H}_{0}$ & 0.218 & $\downarrow 52.3 \%$ & -0.815 & $\mathrm{H}_{0}$ \\
\hline & 4 & KLCI & $\begin{array}{l}0.548 \\
{[0.000]}\end{array}$ & $\begin{array}{l}0.424 \\
{[0.056]}\end{array}$ & $\begin{array}{l}0.554 \\
{[0.009]}\end{array}$ & $\uparrow 30.7 \%$ & 0.515 & $\mathrm{H}_{0}$ & 0.212 & $\downarrow 50.1 \%$ & -0.713 & $\mathrm{H}_{0}$ \\
\hline \multirow{4}{*}{ MENA } & 1 & TA100 & $\begin{array}{l}0.676 \\
{[0.000]}\end{array}$ & $\begin{array}{l}0.500 \\
{[0.021]}\end{array}$ & $\begin{array}{l}0.591 \\
{[0.005]}\end{array}$ & $\uparrow 18.2 \%$ & 0.390 & $\mathrm{H}_{0}$ & 0.232 & $\downarrow 53.6 \%$ & -0.939 & $\mathrm{H}_{0}$ \\
\hline & 2 & MASI & $\begin{array}{l}0.158 \\
{[0.072]}\end{array}$ & $\begin{array}{l}0.498 \\
{[0.022]}\end{array}$ & $\begin{array}{l}0.232 \\
{[0.311]}\end{array}$ & $\downarrow 53.4 \%$ & -0.931 & $\mathrm{H}_{0}$ & 0.077 & $\downarrow 84.5 \%$ & -1.407 & $\mathrm{H}_{0}$ \\
\hline & 3 & TUNINDEX & $\begin{array}{l}0.086 \\
{[0.326]}\end{array}$ & $\begin{array}{l}0.098 \\
{[0.673]}\end{array}$ & $\begin{array}{l}0.451 \\
{[0.040]}\end{array}$ & $\uparrow 360.2 \%$ & 1.163 & $\mathrm{H}_{0}$ & 0.162 & $\uparrow 65.6 \%$ & 0.196 & $\mathrm{H}_{0}$ \\
\hline & 4 & $\begin{array}{l}\text { Amman SE } \\
\text { All Share }\end{array}$ & $\begin{array}{l}0.110 \\
{[0.212]}\end{array}$ & $\begin{array}{l}0.105 \\
{[0.649]}\end{array}$ & $\begin{array}{l}0.585 \\
{[0.005]}\end{array}$ & $\uparrow 457.1 \%$ & 1.694 & $\mathrm{H}_{1}$ & 0.229 & $\uparrow 117.7 \%$ & 0.382 & $\mathrm{H}_{0}$ \\
\hline
\end{tabular}

Notes. The table is based on: (1) the whole sample period from January 2003 to December 2013, (2) the pre-crisis period from September 2005 to May 2007, (3) the crisis period from June 2007 to February 2009. P-values are in brackets. Fisher's Z-statistic (1921) tests null of no contagion. The student's $t$ critical value is 1.688 (at the $10 \%$ significance level).

\section{Empirical Results of Globalization Tests}

Longin and Solnik (1995) stressed that the covariance/correlation matrix of international asset returns plays a special role in the finance literature, as knowledge about its behavior is crucial for the computation of trading portfolios. To test the problem (6), both tests of Jennrich and Larntz and Perlman for equality of the correlation matrices over time are employed. As in Longin and Solnik (1995), our calculations are based on monthly logarithmic returns of stock market indexes. Moreover, the equality of the correlation matrices in two 
subsamples of equal size is tested, see e.g., Chesnay and Jondeau (2001) and Brière et al. (2012). As in subsection, two periods are advocated: (1) the pre-crisis period from September 2005 to May 2007 (21 months) and (2) the crisis period June 2007 to February 2009 (21 months). As mentioned in previous subsections (Figure 2 and Table 3), the empirical results concerning crisis periods for the MENA countries are quite different and heterogeneous, therefore the MENA markets are ruled out from globalization tests.

Table 4

Results of the Globalization Tests by Jennrich (1970) and Larntz and Perlman (1985)

\begin{tabular}{|c|c|c|c|c|c|c|c|c|}
\hline \multirow[b]{2}{*}{ Test periods } & \multicolumn{3}{|c|}{ Jennrich's test } & \multicolumn{5}{|c|}{ Larntz and Perlman's test } \\
\hline & $\begin{array}{c}\text { Test statistic } \\
T_{J}\end{array}$ & $\chi_{(5 \%)}^{2}$ critical value & $\begin{array}{c}\chi^{2} \text { critical value } \\
(10 \%)\end{array}$ & $\begin{array}{c}\text { Test statistic } \\
T_{L P}\end{array}$ & $b_{\alpha}$ & $\begin{array}{l}\text { critical value } \\
(5 \%)\end{array}$ & $b_{\alpha}$ & $\begin{array}{l}\text { critical value } \\
(10 \%)\end{array}$ \\
\hline $\begin{array}{l}2005.9-2007.5 \\
\& \\
2007.6-2009.2\end{array}$ & 112.41 & 114.27 & 108.66 & 2.75 & 3.45 & $\mathrm{H}_{0}$ & 3.25 & $\mathrm{H}_{0}$ \\
\hline
\end{tabular}

Notes. The table is based on: (1) the pre-crisis period from September 2005 to May 2007, (2) the crisis period from June 2007 to February 2009. The table contains the Jennrich's test statistic, given by equation (7), as well as the Larntz and Perlman's test statistic, given by equation (9). The statistics test the null of no globalization. The amount of variables $p=14$.

Table 4 summarizes the globalization tests performed on the whole group containing the S\&P500 and 13 stock indexes of emerging markets (excluding the MENA markets). Due to the space restriction, the correlation matrices are not reported, but they are available upon request. The results based on the Jennrich's test show that the differences in correlation between the two sub-periods are significant only at the 10 percent significance level. On the other hand, no reason can reject the null hypothesis of no globalization effect based on the Larntz and Perlman's test. The results do not explicitly confirm the impact of globalization on world international market interdependence. This evidence is rather not surprising as taking into account that contingent-based regions are considerably diverse with regard to a degree of financial integration, especially in banking. As Brunnermeier (2009) stressed, the 2007 U.S. subprime crisis has been very close to a classical banking crisis. The crisis transmission through financial and banking channels has been very rapid and substantial. Another important piece of evidence from Table 4 is that the Larntz and Perlman's test was found to be more sensitive than the Jennrich's procedure, especially for relatively small sample sizes, as Larntz and Perlman (1985) stated.

\section{Conclusions}

This study contributes to the existing literature by a direct quantitative identification of crisis periods on 17 selected emerging stock markets from four continent-based regions of Europe, Latin America, East Asia, and MENA, in the context of the influence of the 2007 U.S. subprime financial crisis. The period investigated begins in January 2003 and ends in December 2013. The Pagan and Sossounov's methodology (2003) of dividing market states into up and down markets based on monthly logarithmic returns of market indexes is employed. The procedure seems to be useful in locating crisis periods in time. Finally, two periods: (1) the pre-crisis period from September 2005 to May 2007 and (2) the crisis period from June 2007 to February 2009 are advocated.

Additionally, the paper examines the effect of increasing cross-market correlations in the crisis period compared to the pre-crisis period, both in the context of contagion and globalization effects. The standard contemporaneous cross-market correlations and volatility-adjusted cross-correlations, introduced by Forbes and Rigobon (2002), are employed. The results are in accordance with the literature and exhibit that 
heteroskedasticity in market returns biases tests for contagion based on correlation. On the other hand, the results are ambiguous, but it is rather not surprising as a broad-based group of diverse international stock markets is explored. Moreover, to test the global integration effect, the procedures of Jennrich (1970) and Larntz and Perlman (1985) for testing equality of cross-market correlation matrices computed over the pre-crisis and crisis periods are used. The results depend on the test and generally do not confirm the presence of the globalization effect during the 2007 U.S. subprime crisis. Due to the importance of the problem in the context of its practical implications, a possible direction for further investigation would be to study the effect of a turbulent period on international market correlation in an alternative way, for example based on the multivariate Markov-switching model.

\section{References}

Bartram, S. M., \& Bodnar, G. (2009). No place to hide: The global crisis in equity markets in 2008/2009. Journal of International Money and Finance, 28(8), 1246-1292.

Bekaert, G., Harvey, C. R., \& Ng, A. (2005). Market integration and contagion. Journal of Business, 78(1), 39-69.

Bekaert, G., Ehrmann, M., Fratzscher, M., \& Mehl, A. (2014). The global crisis and equity market contagion (Working Paper No. 1352, DIW Berlin).

Brière, M., Chapelle, A., \& Szafarz, A. (2012). No contagion, only globalization and flight to quality. Journal of International Money and Finance, 31, 1729-1744.

Brunnermeier, M. K. (2009). Deciphering the liquidity and credit crunch 2007-2008. Journal of Economic Perspectives, 23(1), 77-100.

Bry, G., \& Boschan, C. (1971). Cyclical analysis of time series: Selected procedures and computer programs. New York: NBER.

Calomiris, C. W., Love, J., \& Martinez Peria, M. S. (2012). Stock returns' sensitivities to crisis shocks: Evidence from developed and emerging markets. Journal of International Money and Finance, 31(4), 743-765.

Chesnay, F., \& Jondeau, E. (2001). Does correlation between stock returns really increase during turbulent periods? Economic Notes, 30, 53-80.

Chudik, A., \& Fratzscher, M. (2011). Identifying the global transmission of the 2007-2009 financial crisis in a GVAR model. European Economic Review, 55, 325-339.

Claessens, S., Dell'Ariccia, G., Igan, D., \& Laeven, L. (2010). Cross-country experience and policy implications from the global financial crisis. Economic Policy, 62, 267-293.

Cooper, M. J., Gutierrez, R. C. Jr., \& Hameed, A. (2004). Market states and momentum. Journal of Finance, 59(3), $1345-1365$.

Didier, T., Love, I., \& Martinez Peria, M. S. (2012). What explains comovement in stock market returns during the 2007-2008 crisis? International Journal of Finance and Economics, 17, 182-202.

Dooley, M., \& Hutchison, M. (2009). Transmission of the U.S. subprime crisis to emerging markets: Evidence on the decoupling-recoupling hypothesis. Journal of International Money and Finance, 28(8), 1331-1349.

Doornik, J. A., \& Hansen, H. (2008). An omnibus test for univariate and multivariate normality. Oxford Bulletin of Economics and Statistics, 70, 927-939.

Edwards, S. (2000). Contagion. World Economy, 23(7), 873-900.

Fabozzi, F. J., \& Francis, J. C. (1977). Stability tests for alphas and betas over bull and bear market conditions. Journal of Finance, 32(4), 1093-1099.

Fisher, R. A. (1921). On the probable error of a coefficient of correlation deduced from a small sample. Metron, 1, 3-32.

Forbes, K. J., \& Rigobon, R. (2002). No contagion, only interdependence: Measuring stock market comovements. Journal of Finance, 57(5), 2223-2261.

Frank, N., \& Hesse, H. (2009). Financial spillovers to emerging markets during the global financial crisis. Finance a Uver: Czech Journal of Economics and Finance, 59(6), 507-521.

Goetzmann, W. N., Li, L., \& Rouwenhorst, K. G. (2005). Long-term global market correlations. Journal of Business, 78(1), 1-38.

Hong, Y., Tu, J., \& Zhou, G. (2007). Asymmetries in stock returns: Statistical tests and economic evaluation. Review of Financial Studies, 20(5), 1547-1578. 
Jennrich, R. I. (1970). An asymptotic chi-square test for the equality of two correlation matrices. Journal of the American Statistical Association, 65, 904-912.

Kearney, C. (2012). Emerging markets research: Trends, issues, and future directions. Emerging Markets Review, 13(2), $159-183$.

Lagoarde-Segot, T., \& Lucey, B. M. (2009). Shift-contagion vulnerability in the MENA stock markets. The World Economy, 32(10), 1478-1497.

Lane, P. R., \& Milesi-Ferretti, G. M. (2011). The cross-country incidence of the global crisis. IMF Economic Review, 59(1), 77-110.

Larntz, K., \& Perlman, M. D. (1985). A simple test for the equality of correlation matrices (Technical Report No. 63, Department of Statistics, University of Washington).

Lee, J. S., Kuo, C. T., \& Yen, P. H. (2011). Market states and initial returns: Evidence from Taiwanese IPOs. Emerging Markets Finance \& Trade, 47(2), 6-20.

Longin, F., \& Solnik, B. (1995). Is the correlation in international equity returns constant: 1960-1990? Journal of International Money and Finance, 14(1), 3-26.

Longin, F., \& Solnik, B. (2001). Extreme correlation of international equity markets. Journal of Finance, 56(2), 649-676.

Lunde, A., \& Timmermann, A. (2000). Duration dependence in stock prices: An analysis of bull and bear markets (University of California, San Diego).

Marer, P. (2010). The global economic crises: Impact on Eastern Europe. Acta Oeconomica, 60(1), 3-33.

Mun, M., \& Brooks, R. (2012). The roles of news and volatility in stock market correlations during the global financial crisis. Emerging Markets Review, 13(1), 1-7.

Neaime, S. (2012). The global financial crisis, financial linkages and correlations in returns and volatilities in emerging MENA stock markets. Emerging Markets Review, 13, 268-282.

Ocampo, J. A. (2009). Latin America and the global financial crisis. Cambridge Journal of Economics, 33, 703-724.

Olbrys, J., \& Majewska, E. (2014a). Quantitative identification of crisis periods on the major European stock markets. La Pensee, $76(1), 254-260$.

Olbrys, J., \& Majewska, E. (2014b). Direct identification of crisis periods on the CEE stock markets: The influence of the 2007 U.S. subprime crisis. Procedia Economics and Finance, 14, 461-470.

Pagan, A. R., \& Sossounov, K. A. (2003). A simple framework for analysing bull and bear markets. Journal of Applied Econometrics, 18(1), 23-46.

Pericoli, M., \& Sbracia, M. (2003). A primer on financial contagion. Journal of Economic Surveys, 17(4), 571-608.

Reinhart, C. M., \& Rogoff, K. S. (2009). The aftermath of financial crisis. American Economic Review: Papers \& Proceedings, 99(2), 466-472.

Rigobon, R. (2002). Contagion: How to measure it? In S. Edwards, \& J. A. Frankel (Eds.), Preventing currency crises in emerging markets. Chicago: University of Chicago Press.

Rose, A. K., \& Spiegel, M. M. (2012). Cross-country causes and consequences of the 2008 crisis: Early warning. Japan and the World Economy, 24, 1-16.

Yilmaz, K. (2010). Return and volatility spillovers among the East Asian equity markets. Journal of Asian Economics, 21, 304-313. 